\title{
LÍMITES DE LA LIBERTAD DE EXPRESIÓN, FLANCOS DE LA VERDAD DE LO EXPRESADO: LA INDEPENDENCIA DE JOSÉ MARÍA BLANCO WHITE EN EL ESPAÑOL
}

\author{
FRONTIERS OF FREEDOM OF EXPRESSION, SIDES OF THE \\ TRUTH OF WHAT IS EXPRESSED: THE INDEPENDENCE OF \\ JOSE MARÍA BLANCO WHITE IN EL ESPAÑOL
}

\section{VIRGINIA GIL AMATE*}

\section{RESUMEN}

Este artículo estudia los márgenes de la libertad de expresión en la que se desarrolló la publicación del periódico El Español de José María Blanco White. Con tal fin, se contrastan los escritos públicos y privados del autor, así como diversas cartas e informes relativos a Blanco y se analizan sus sistemas expresivos.

Palabras clave: José María Blanco White, El Español, siglo XIX, América, independencia.

\section{ABSTRACT}

This article studies the frontiers of freedom of expression in which the publication of the newspaper El Español of José María Blanco White developed. For this purpose, the public and private writings, as well as different letters and reports concerning Blanco, are properly tested against and their expressive systems analysed.

Keywords: José María Blanco White, El Español, 19th century, America, independence.

Recibido: 08.04.16. Aceptado: 10.07.17.

* Profesora Titular del Departamento de Filología Española de la Universidad de Oviedo. Investigadora del Instituto Feijoo de Estudios del Siglo XVIII de la Universidad de Oviedo. Investigadora de la Unidad Singular de Investigación en Literatura Hispanoamericana de la Universidad de Alicante. Oviedo, España. Correo: vigia@uniovi.es 
$\mathrm{E}$ N el NÚMERo VII de El Español, José María Blanco White afirmaba haberse ido de España "para no tener que expresar mis opiniones a medias" (30/X/1810: 64). Tal declaración no abarca la totalidad ni la profundidad de índole personal, descrita en su autobiografía ${ }^{1}$ y diseminada en sus Cartas desde España, de la razón que guió su meditada expatriación, unida a la voluntad de deshacerse de la máscara vital que para él era su condición de sacerdote católico. La decisión implicaba acarrear con el dolor que causaría en su entorno más íntimo romper con las bases de una educación tradicional y enfrentarse a un porvenir del que no conocía ni el futuro inmediato. Por eso fue una determinación largamente pensada y demorada durante décadas que algo, pero no todo, tiene que ver con el libre ejercicio de la opinión. Puede corroborarse en la multitud de páginas que llenó el autor con reflexiones personales, donde se muestra bastante más preocupado por armonizar su pensamiento con su vida, es decir, por no vivir condicionado por las pautas de ningún grupo o creencia colectiva, que por la tensión que le genera a cualquier persona honrada contemplar los límites de la libertad de expresión o brear con el espantajo de la censura.

$\mathrm{Si}$ de lo expuesto en sus libros pasamos a los hechos que construyen su biografía, encontraremos que, en las difíciles circunstancias políticas de los años previos a su salida de España, Blanco no siempre practicó la resistencia ante lo que no se quiere decir. La oda "La verdad", que leyó en honor de Godoy mientras formaba parte del Instituto Pestalozziano en 1808, iba bastante más allá del ejercicio de asordinar el pensamiento. Que esta composición se convirtiera en uno de los trazos de la caricatura con la que su figura se despedía del siglo XIX y comenzaba a atravesar el siglo XX, no le merma importancia ni la convierten en anecdótica. Al contrario, es un ejemplo aislado de aquello que hizo para mantener su trabajo en Madrid, alejado de las vicarias sevillanas, pagando "el tributo exigido por un poder que detestaba, pero al cual necesitaba" (Durán, 2005, p. 102).

No obstante, no siempre es un límite externo a un autor aquel que traza la frontera de lo que éste quiere (o puede) expresar. En el caso de Blanco, años después de la experiencia de El Español, publicaría sus Letters from Spain, detallando los márgenes de libertad que se concedió para redactarlas

\footnotetext{
${ }^{1}$ La autobiografía de José María Blanco White, editada en 1845 en Londres por John Hamilton Thom bajo el título The Life of the Reverend Joseph Blanco White, written by himself with portions of this correspondence, la forman tres partes diferenciadas, la primera de ellas, Narrative of his Life in Spain and England, fue traducida y editada por Antonio Garnica bajo el título Autobiografía de Blanco White (Blanco White, 1975).
} 
porque, como escritor dotado de talento y de conocimiento literario, no le faltaron formas expresivas para encauzar las cosas que quería decir. Las Cartas incidían desde el título en el artificio de la voz narrativa, presentando la focalización de la mirada tanto como el asunto observado, cosa que no se aprecia en la edición española al optar por traducir Cartas de España, cuando su original no marca tanto el asunto ("de") como el lugar ficcional en el que se sitúa el narrador ("desde"). Suma a ello otros recursos narrativos, entre los que se encuentran la localización temporal de los textos en el pasado con respecto al momento de la publicación; la situación del supuesto autor, de regreso a España después de un largo y voluntario abandono del país natal; y el nombre del sujeto emisor, donde la dualidad del apelativo que adquirió en Londres se trasmuta en Leucadio Doblado. Este retórico distanciamiento, tan de moda en la época, iba unido a la discreción que Blanco perseguía, explicada, en carta a su hermano Fernando (9/V/1822), como el "decente velo" (1971, p. 352) con el que cubría, en las Cartas, tanto su persona como la intimidad o el nombre de sus seres queridos. Al redactar, años después, su autobiografía, esta vez adoptando la forma de una carta personal dirigida al Dr. Whately (aunque en numerosas ocasiones el autor se salte el recurso amplificando la figura del receptor hacia los directos lectores para los que escribía, el público inglés), Blanco analiza el valor que necesitó, en las Cartas, para hablar de sus padres, de su formación religiosa y de su ruptura con la tradición hispánica, cuando comienza a narrar su salida de España con el temor de rememorar esa etapa, por si abría las antiguas heridas. Sin embargo, piensa, apoyándose en la preceptiva literaria, que la escritura autobiográfica le librará del desgarro puesto que esta puede describir sin volver a la médula de la experiencia, puede transitar la memoria evitando la imaginación. Es decir, su narración no estará obligada a recrear una emoción, dedicándose nada más (y nada menos) al recuento de lo pasado (Blanco White, 1975, p. 162).

Las reflexiones de Blanco White sobre los modos de escritura para encaminarse a unos fines comunicativos previamente fijados, tienen un añadido en la creación de su heterónimo Juan Sintierra en El Español, porque éste, desde su rotunda subjetividad, podrá decir, con gracia y no poca malicia, todo aquello que un periodista imparcial debía evitar. Sin embargo, el recurso termina deliberadamente en paradoja puesto que la primera de sus cartas se edita en marzo de 1811, después de que el periódico y su editor sufrieran las críticas frontales de la Junta de Cádiz y la prohibición de la circulación de El Español en los territorios americanos. El viejo apátrida se presenta, entonces, declarando que su reputación está menos tocada que la

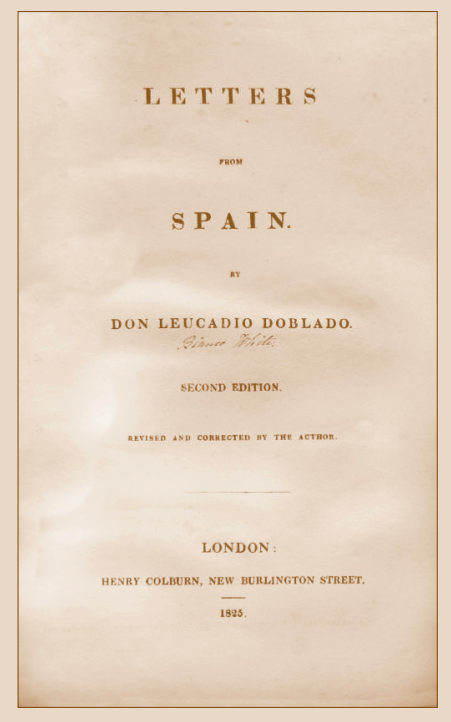


del editor y que, por tanto, Blanco acogerá en las páginas de su periódico lo que el mismo Juan Sintierra no se atrevería a publicar bajo su nombre ( $E l$ Español, XII, 30/III/1810, p. 451).

El irónico baile de atribuciones se ampliará en otra carta al hilo del decreto de libertad de imprenta emitido por las Cortes y la situación de proscripción de El Español. Juan Sintierra barruntará que esa flagrante contradicción entre la ley y la práctica quizá se deba a que él "no pertenece a la nación" (El Español, XVI, 30/VI/1811, p. 294), aunque no le parece razón suficiente porque sí "Pertenece a ella el autor del Español que se vale de los pensamientos de Juan Sintierra" (El Español, XVI, 30/VI/1811, p. 294). Así las cosas, no extrañará que en el número XXI de diciembre de 1811 sea Blanco el que "ha suplicado a su amigo Juan Sintierra que le escriba casi todo ese número" (El Español, XXI, 30/ XII/1811, p. 220), esta vez no por asuntos relacionados con el contenido o el emisor sino para asegurar y ampliar la recepción de sus noticias (El Español, XXI, 30/ XII/1811, p. 220).

Todo esto son recursos retóricos que muestran las variadas formas adoptadas por Blanco para encauzar la narración o el pensamiento y, por supuesto, entran dentro de las modas expresivas en la época. Veamos ahora cómo encarrilaba la tensión entre el deber de informar y los límites políticos, económicos y personales que marcaron su labor periodística durante sus últimos años en España y los primeros en Inglaterra, en concreto los que atañen al Semanario Patriótico y a El Español.

Su primera incursión en un periódico se la brindó Manuel José Quintana al encomendarle, junto a Isidoro Antillón, la dirección de la segunda etapa del Semanario Patriótico. En su autobiografía Blanco apunta que ambos desarrollaron su trabajo "con toda honestidad e independencia" (1975, p. 152). El marco histórico y las circunstancias políticas españolas habían propiciado una apertura hacia las ideas de los liberales, pero la libertad de prensa no estaba decretada, cualquier escrito debía someterse a la censura. Por suerte para Blanco y Antillón la decisión de publicación estaba en manos de Quintana, "que nos daba libertad total bajo su responsabilidad" (1975, p. 152). Aun así, por juventud, por inexperiencia, por temor, por prudencia, por educación, cualquiera sabe ya que Blanco no esgrime razón concreta alguna, practicaron una autocensura no lesiva con sus propias convicciones:

... no nos atrevimos a dar rienda suelta a nuestras plumas, pero recíprocamente nos comprometimos a que en nuestros escritos no apareciera nada que pudiera sonar a halagos a los hombres en el poder y a que el Semanario nunca fuera instrumento para engañar al pueblo (1975, p. 152). 
La empresa de El Español se hizo bajo circunstancias bien diferentes, con Blanco dotado de la determinación y la fortaleza necesarias para haber puesto distancia con todo aquello, la Iglesia, la patria, la familia, que le impedía ser dueño de su propia vida y desde Londres, bajo la garantía de las libertades públicas británicas. Sin embargo, a juzgar por las cartas que se cruzó con Lord Holland, John Allen, Robert Southey, Charles Richard Vaughan o con el marqués de Wellesley, así como por los despachos del Foreign Office y las comunicaciones internas entre destacados responsables de la política internacional británica, no estuvo al margen de presiones. No pudo ser Blanco tan independiente como quería, puesto que la amistad de sus protectores ingleses tampoco fue ajena al importante papel que una publicación como El Español podía jugar en el equilibrio de poder entre Francia y Gran Bretaña y en el beneficioso mercado que los territorios de la América hispánica podían ofrecer al comercio británico. Ya avisó Antonio Garnica que Blanco descubrió en Inglaterra, en lo tocante a asuntos religiosos, que la intolerancia y el acoso ante la posible disensión personal "no tiene fronteras, y sólo se manifiesta de forma diferente en circunstancias diferentes" (Blanco White, 1975, p. 17), ¿qué no pasaría, entonces, en el ámbito político, en el de los intereses nacionales, en el de los lucrativos negocios y en el de la utilidad práctica que el periodismo podía prestar en cada uno de esos espacios?

El cuestionamiento de la figura de Blanco White y de la labor de El Español como correa de transmisión de las pretensiones británicas comenzó con las acusaciones personales y políticas que desde las liberales Cortes de Cádiz se le hicieron y continuó, posteriormente, desde posturas fuertemente conservadoras. Estas, tal cual habían hecho sus coetáneos, no dudaban en considerarlo un "Protegido y aún subvencionado por lord Holland (el sobrino de Fox), por M. John Jorge Children y por M. Ricardo Wellesley" (Menéndez Pelayo, 1967, p. 800). Si la acritud ante Blanco fue la misma al principio y al final del siglo XIX, en nuestros días, sin embargo, hay una tendencia a atenuar, o a no admitir, los cargos que de forma desabrida se le imputaban al editor de El Español, esto es, la vinculación directa de su periódico con los intereses del gobierno británico. Vicente Llorens, por ejemplo, establecía una relación política difusa entre el periódico y los amigos ingleses de Blanco y consideraba nula, a pesar de las suscripciones, la protección o la injerencia gubernamental en la empresa ${ }^{2}$. Por su parte, para

\footnotetext{
2 "Blanco en Londres se dedicó a emprender por su cuenta la publicación de un periódico en español. Y como iba a tener por objeto defender la causa de España y la alianza con Inglaterra
}

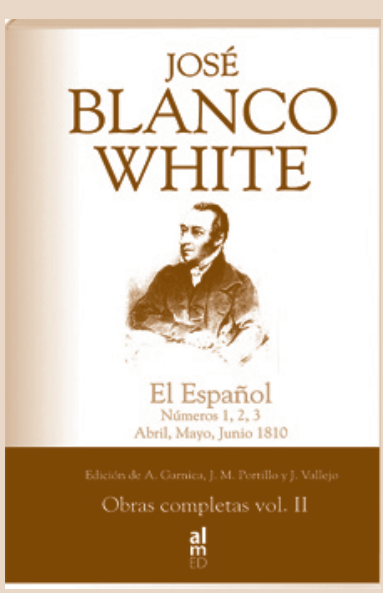


André Pons la evidencia de la "total concordancia de puntos de vista entre el Gobierno británico y El Español" (2006, p. 68-69), al menos en los asuntos relativos a América y a partir del tercer número del periódico, se debía a la ayuda intelectual, la influencia política y la amistad de "los dos asesores whig" (p. 65), Lord Holland y John Allen, de Blanco. No aprecia, por tanto, intervención directa, ni siquiera intervención alguna, del Foreing Office en los asuntos de El Español aunque, curiosamente, "las tesis y la actitud de $E l$ Español eran las mismas que habrían sido adoptadas si el periódico hubiera recibido instrucciones directas del Foreign Office" (p. 69). Para probar tan difícil postulado, Pons recurre, como van a hacer buena parte de los más rigurosos conocedores de su figura, al "carácter de Blanco White, a quien le importaba por encima de todo su independencia" (p. 70) y zanja las acusaciones de traición que se le cursaron desde Cádiz apuntalando, en nuestra época, el cariz descerebrado que Blanco, en la suya, achacó a la política española, puesto que ni liberales ni conservadores supieron ver que El Español no iba "en contra de los intereses de España" (p. 70), que tan sólo defendía "en lo económico sobre todo (...) los intereses de Inglaterra; en contra de los intereses de los monopolistas gaditanos" (p. 70).

Nadie duda hoy en día del puesto central que Lord Holland ocupó en la profunda y rápida evolución ideológica experimentada por Blanco a partir de 1810; sí ha cambiado, sin embargo, el significativo tono de chanza con el que Menéndez Pelayo calificaba la relación. Este se ha vuelto ahora más comprensivo con Blanco que con la iracundia de las Juntas y tiene gradaciones variadas. Puede ir del "asesoramiento" señalado por Pons, a lo que Martin Murphy considera "la benigna influencia de su mentor" (Blanco White, 2010, p. 13), Lord Holland, al que se debería también la idea de la creación de El Español:

Aunque fue una sorpresa para él (y para Lady Holland) la llegada de Blanco a Londres en febrero de 1810, pronto se dio cuenta de que su protegido podría servir un fin útil como editor de un periódico que fomentara la unidad entre Londres y Cádiz (Blanco White, 2010, p. 15).

La postura de Manuel Moreno Alonso es más bien una defensa a ultranza en la que se decreta que la sintonía entre las posturas británicas y

frente a Napoleón, creyó posible al principio obtener alguna ayuda del gobierno inglés. Pero no fue así. Pudo contar, sin embargo, con otras asistencias. Lord Holland, las casa Gordon y Murphy y otras sociedades comerciales anglo-españolas se suscribieron a numerosos ejemplares" (Blanco White, 1971, p. 2). 
la línea editorial de El Español no responde a connivencia alguna. Se basa para tal afirmación, tal cual hizo Pons, en la personalidad de Blanco, que hace emanar de discutibles determinismos nacionales, "obsesiones, repentes y honestidades propias de un hispano-irlandés" (2002, p. 133), y de las insistentes declaraciones de Blanco sobre su independencia personal, todo lo cual conduce a que "no es posible dudar ni de su sinceridad ni de su buena fe" (135) o, lo que quizá sea más difícil, a no poder "dudarse que el editor actuó en libertad de concepción y expresión de opiniones, e incluso con honradez" (135). Si bien para Fernando Durán la independencia de Blanco White está a salvo de las dudas que le atribuyeron "los maliciosos" (2005, p. 171) en su época y "los malpensados" (207) después, su investigación biográfica va abriendo flancos en espacios que quizá se querían cerrar. Así, si Pons estudió las suscripciones que permitieron la pervivencia de $E l$ Español (entre las que se encontraban la de Lord Holland, la de la embajada británica en Cádiz, la de la empresa Gordon y Murphy y la de otras sociedades británicas con intereses en América), Durán advierte que estas no eran exactamente filantrópicas ${ }^{3}$. La conclusión es obvia -"Estaba claro a quien beneficiaba el periódico" (160)- aunque no le conduce a una resolución indiscutible puesto que, en la línea de Pons, Durán separa el provecho de la intromisión al considerar la existencia de "pruebas de que el editor no se conducía por las órdenes de nadie" $(160)^{4}$ de ahí que las hipotéticas "instrucciones ni existieron ni hacían falta" (188).

\footnotetext{
3 "durante bastante tiempo fue rentable [El Español], aunque no dejase grandes beneficios; su distribución fue más amplia de la que gozase cualquier periódico español de su tiempo. Ahora bien, gran parte de su venta consistía en suscripciones, digámoslo así, políticas, que contrataron el gobierno y las casas comerciales británicas. En eso reside el auténtico compromiso de El Español con los designios británicos; en cuanto vieron la utilidad que les redundaba su mensaje lo apoyaron sin contemplaciones" (Durán, 2005, p. 159).

${ }^{4}$ Las pruebas aducidas son la carta que Blanco envío a Lord Wellesley el 25 de septiembre de 1810 (Blanco White, 2010, pp. 314-315), así como la comunicación interna entre Hamilton y Vaughan de 12 de mayo de 1810, en el que el primero señalaba "el carácter de ese hombre" (Blanco White, 2010, p. 362), en el original: "the character of the man" (Blanco White, 2010, p. 361), para aludir al estilo bronco o mordaz ("acrimonious" (Blanco White, 2010, p. 361)) que habían provocado las protestas de la Regencia. Para Durán, "El hombre era bien conocido: no se le podían dar consignas" (2005, p. 161), y bien puede ser así o estar indicando un juicio que va más allá de Blanco, afectando tanto a la perspectiva con la que la diplomacia británica juzgaba la ideología de los liberales (no otra era la tendencia de Blanco en los inicios de El Español), como a la idea que tenían de la idiosincrasia hispánica, puesto que el párrafo completo es el que sigue: "Usted en cambio sabe lo suficiente del carácter de ese hombre, las causas que defiende, y el país para el que escribe, para hacer innecesario que yo añada nada más" (Blanco White, 2010, p. 362). Efectivamente, la carta indica que Blanco ha escrito el primer número sin control del Foreing Office y que en el futuro no volverá a consentirse que el periódico dañe las relaciones exteriores británicas, de ello dependerá la suscripción de 100 ejemplares que tenían contraída.
} 
Veamos ahora lo que el propio José María Blanco White dejó escrito sobre estas cuestiones ya que fue bien consciente, puesto que las acusaciones fueron públicas, de la consideración de agente británico en que lo tuvieron sus compatriotas. "En Cádiz", anotará años después en su autobiografía, "todo el mundo creía que estaba pagado por el gobierno inglés con el propósito imaginado por ellos de apoderarse de aquella ciudad y de las colonias españolas" (1975, p. 189). La desolación que sintió en el momento de las críticas ha remitido cuando narra su vida, no así el afán por defender su honor. "El fin de estas memorias", señalará, "es remover las ideas falsas con respecto a mi persona" (1975, p. 229), de ahí que dedique un amplio espacio a aclarar la vinculación de su periódico con las autoridades británicas y las suyas con sus amigos ingleses. Para empezar, Blanco marca grados de relación e influencia diferentes. A Richard Wellesley, no a Lord Holland, atribuye la sugerencia de la creación de un periódico y el contacto para iniciar la empresa (182). La intervención no pasaría de ahí, al no tener aquel "mucha influencia con su padre Lord Wellesley" (182), por lo que del "éxito final no le debo nada a mi consejero" (182). La cosa cambia en el caso de Lord Holland y John Allen, estos serán considerados, dos décadas después, "maestros" o "jueces y consejeros tan capacitados" (205) que sus "observaciones" (205) fueron "los mejores medios que tenía de perfeccionarme en mi tarea" (205). Es importante tener en cuenta que Blanco, salvo su breve paso por las páginas del Semanario Patriótico, no había entrado en el ámbito de la política, mucho menos en las sutilezas de la política internacional, y afrontó la tarea que le esperaba en El Español en paralelo a un drástico cambio ideológico, de las ideas liberales de ascendencia francesa que había mantenido en España, a las conservadoras y monárquicas que iba a adquirir en Inglaterra. Además de ello, en Londres fue descubriendo la magnitud del papel que jugaba su periódico mientras realizaba el titánico esfuerzo de sacarlo adelante aunque, en el recuento de su vida, achaque al impresor Juigné, y no a los intereses británicos que sin embargo apostaron económicamente por la empresa ${ }^{5}$, cualquier estrategia preconcebida:

Entre los emigrantes franceses que residían en Londres en el tiempo de mi llegada había un sacerdote llamado Juigné, que se había hecho impresor. Es posible que tuviera algún previo conocimiento de este negocio, porque de otra manera no hubiera conseguido el éxito que tuvo.

\footnotetext{
${ }^{5}$ Durán advierte que el Foreign Office pagaba al impresor 250 libras, las mismas que, una vez liberado del contrato con Juigné, recibirá directamente Blanco (2005, pp. 162-163)
} 
Dulau me dirigió a este hombre como la persona idónea que no dudaría en aprovechar la oportunidad de publicar un periódico español en Londres. Yo desconocía completamente la importancia que la situación política de España y sus colonias añadían a mis cualidades personales para ser el editor o, para hablar más objetivamente, el único escritor del periódico (1975, p. 183).

Cuando pasa revista a esa etapa de su vida, dos décadas después y sin que haya desaparecido del todo el ánimo de autodefensa, considera que no hubo "nada que torciera mi juicio, de no ser que haya dado demasiado peso a la amistad y al afecto" (1975, p. 206) de Lord Holland y Allen. Aun así, con ánimo de zanjar cualquier duda sobre su autonomía intelectual con respecto a las instancias gubernamentales, esgrime el hecho de que Lord Holland estuviera en la oposición parlamentaria "durante todo el tiempo que duró mi periódico" (1975, p. 205). El alegato no es muy sólido, por eso ha servido tanto para alejar al periódico de la injerencia directa, como para establecer una de las correas de transmisión entre las aspiraciones británicas, fundamentalmente las relativas a los territorios americanos, y El Español, sobre todo si tenemos en cuenta, siguiendo a Durán (2005, p. 227), que Lord Holland podía ser contrario a los planteamientos internos del gobierno tory pero no eran distintas sus miras en lo referido a la política exterior.

Como estamos viendo, los escritos de Blanco inciden en defender su independencia (en el sentido de que él creía en las cosas que escribía) y en destacar la ausencia de parcialidad que guio su actuación periodística. Sin embargo, ambas cosas tienen un serio correctivo, quizá no advertido por el propio autor, en el artículo que publicó para contestar la prohibición de circulación de El Español en América. Ahí declaró que su periódico defendía la causa de España en cualquier frente con activas estrategias discursivas que no siempre coincidían con su pensamiento o con lo que consideraba la verdad de los hechos:

Examínense, sí, examínense todas las páginas de mi periódico, y se verá, que en consideración á la España, que no tenía otro centro que la Regencia, jamás escribí un rasgo en contra de ella: defendí su legitimidad, buscando rodeos á falta de razones: hablé de ella en términos de respeto, aún cuando cometió los mayores absurdos. Procuré distraer á los Americanos de los argumentos con que la atacaban. Callé, en fin, las intrigas con que estaban queriendo impedir las cortes, por no escandalizar á las Américas, y por no destruir los medios de conciliación que presentaban respecto a la Metrópoli (El Español, XI, 28/II/1811, pp. 350-351). 
Nada para alarmarse, de ahí que inserte tal declaración en el periódico, puesto que la prensa del XIX no concebía la labor informativa sin mezclarla con la tarea de crear, o dirigir, una determinada opinión pública. Es necesario, entonces, atender a las cartas de Blanco para calibrar las condiciones en las que llevó a cabo la edición de El Español y las intromisiones que soportó conscientemente.

En carta a Lord Holland fechada el 29 de abril de 1810, Blanco indica las particulares dificultades a las que se enfrenta al editar un periódico sobre asuntos españoles en Inglaterra, de ahí que salude "con efusivas gracias" (Blanco White, 2010, p. 28) la suscripción efectuada por Holland y lamente que el gobierno británico "no parece inclinado a apoyar" (Blanco White, 2010, p. 28) su empresa. A Lord Holland, entusiasmado desde el principio con el proyecto, no le defraudará el primer número, según le dice a comienzos de mayo de 1810. Aprecia la "diligencia, juicio, argumento e ingenio" (Blanco White, 2010, p. 30) de Blanco y aprovecha para mostrar el punto estratégico, combatir a Bonaparte, que para él representará El Español. Desde ese comentario inicial, sus observaciones irán dirigiéndose, en mensajes posteriores, hacia un asedio sin cuartel a las ideas francesas, compartido en proporción ascendente por Blanco.

La carta de John Allen de 23 de junio de 1810 tiene matices diferentes al establecer una relación más informativa por ambas partes. Su tono es el de un igual transmitiendo a Blanco la negativa impresión que El Español ha causado entre los miembros de la Junta, así como las ideas básicas e innegociables que, con respecto a América, deberían seguirse en España. A saber, la derogación de cualquier traba a la libertad de comercio y la incorporación de los criollos en el gobierno y la administración de sus virreinatos de origen. A partir de esas zonas inaugurales quedará clara la situación de Blanco, al menos en lo que puede apreciarse a través de la correspondencia. Sus amigos ingleses apoyarán, moral y económicamente, su empresa periodística, lo pondrán al tanto y, en ocasiones, intentarán neutralizar las críticas que El Español recibe en la península sugiriéndole, fundamentalmente Holland, la actitud más oportuna para apaciguar los ánimos. Estas pueden ir de la conveniencia de reseñar libros de los personajes más irritados con la línea del periódico, a la recomendación de enfocar las críticas a la Junta Central distinguiendo las actuaciones particulares de los vocales; o bien, de la invitación a tratar determinados asuntos de la actualidad política, a la conminación que supone el "usted debería exhortar", "debería reprobar" (Blanco White, 2010, p. 85), enviada por Lord Holland el 14 de octubre de 1810, hasta la definitiva intromisión, en carta de finales de ese mismo mes: 
Le adjunto un esbozo apresurado de algunos de los temas que supongo urgente imprimir en su próximo Español y reconozco que espero que su primera parte contenga más documentos de periódicos americanos y más materia directamente aplicable al presente estado de las cosas que las primeras 20 páginas de su último número (Blanco White, 2010, p. 113).

Hay una diferencia sustancial entre la actitud que muestra Blanco en sus cartas, empeñado en recabar documentación para ser "imparcial" (Blanco White, 2010, p. 40) ante los hechos, sobre todo los sucedidos en territorios americanos, y la de Holland, bastante más pragmático en cuanto a las campañas que El Español debía sostener. No difieren, sin embargo, en la distancia que media entre sus opiniones personales y la línea editorial que el periódico sostenía en asuntos que fueron puntos clave de su ideario. Por ejemplo, Lord Holland podrá defender la necesidad de que los criollos tengan una amplia representación en la Junta de Cádiz pero, en su correspondencia con Blanco quedará calculada la jugada no como una medida política justa sino como un medio para tener aplacados, e incluso contentos, los ánimos de los americanos puesto que la distancia ocasionará que "nunca estarán todos presentes mientras se reúnan las cortes en Europa" (Blanco White, 2010, pp. 94-95) y la labilidad humana hará el resto en los pocos que lleguen:

nueve de cada diez estarán hasta cierto punto influidos por el interés, el miedo, la conversación o la nueva conexión y se dejarán llevar por la corriente de opinión popular de la asamblea (Blanco White, 2010, p. 95).

Postura esta que no debió incomodar a Blanco -pero sí puede mermar la categoría de convicciones personales atribuida a las ideas que defendía en El Español- ya que su opinión sobre la población americana respondía al nefasto estereotipo con el que se caracterizaba, salvo excepciones, a los americanos y a América, desde el siglo XVIII ${ }^{6}$. No obstante, en la contestación

\footnotetext{
6 "Los americanos descendientes de españoles son naturalmente despiertos e inteligentes, pero les suele faltar principios morales y firmeza de carácter. Criados en un clima que invita al pleno disfrute de los placeres sensuales y sometidos a un gobierno que obstaculiza todo medio de cultivar las virtudes varoniles, las mejores clases de la sociedad hispanoamericana son superficiales y blandengues, en tanto que las clases más bajas están hundidas en el más craso libertinaje [...]. Si hay un defecto característico de todas las clases sociales es sin duda la habitual despreocupación por las obligaciones morales. Sería inútil tratar de persuadir a las mejores clases de Hispanoamérica que los deberes morales se extienden a la política y al gobierno: son incapaces de creer (y en esto hay que incluir a un buen número de españoles) que el peculado y la aceptación de sobornos son males morales" (Blanco White, 1975, p. 199).
} 
a la "Carta de un americano al Español" esconde sus prejuicios y declara que los comportamientos humanos son iguales bajo iguales circunstancias -"No pretendo con esto echar tacha alguna sobre el carácter de los Criollos; lo que aqui digo de esta parte de la poblacion de América, se verificaria igualmente en qualquiera otra nación que se hallase en sus circunstancias" (El Español, n. XXIV, 30/IV/1810, p. 421)-. Menos de dos años después, en informe privado cursado a William Hamilton, subsecretario del Foreign Office, basaba el deseo (que él presuponía) de reconciliación con España de los americanos, en "La natural indolencia de los indios y criollos" (Blanco White, 2010, p. 225).

Puede verse en las páginas de El Español que el periódico apoyó la representación "justa" de todos los territorios hispánicos en las Cortes de Cádiz, convirtiendo el asunto en una de sus causas centrales y en uno de los ejes de su abierta crítica a la política española; también puede leerse en la autobiografía de Blanco que para él la labor de los diputados de Indias en las Cortes se redujo a haber votado y actuado "constantemente del lado de los reformadores, menos cuando había alguien que les ofreciera dinero" (1975, p. 201). Por tanto, en este asunto, en el de considerar El Español un periódico que defendió a los americanos ${ }^{7}$, no sería una sutileza innecesaria acotar estrictamente las miras del periódico a la defensa de una causa americana porque esta atentaba contra las líneas políticas de las Cortes de Cádiz, buscando, más que beneficiar a aquellos, desestabilizar a esta.

Por su parte, la conveniencia de la ambigüedad se vuelve paradigma cuando toca hablar de la libertad de prensa. Que este sea un punto fundamental del ideario de Lord Holland, que celebre, en carta a Blanco de 9 de abril de 1813 (Blanco White, 2010, pp. 145-150), su inclusión constitucional como uno de los logros de las Cortes de Cádiz, no es obstáculo para haberle indicado a Blanco, en el comienzo de la andadura de El Español, el peligro que entrañaría para el periódico enfrentarse a los intereses del gobierno británico, aconsejándole, además, mostrar docilidad y disposición a aceptar las directrices del Foreign Office en lo concerniente a asuntos españoles:

Su periódico está haciendo mucho bien y no puedo sino percibir que si nuestro gobierno realmente se volviera hostil a él, su circulación se vería disminuida o incluso detenida y todo ese bien consecuentemente frustrado. A no ser por tanto que le hagan a usted peticiones que, si se

\footnotetext{
${ }^{7}$ Dos visiones dispares de este asunto pueden encontrarse en la defensa del "americanismo" de Blanco en la introducción de Manuel Moreno Alonso a José María Blanco White (1993); y en el cuestionamiento del mismo en Roberto Breña (2002).
} 
cumplieran, frustrarían todos los buenos propósitos de su publicación, usted estaría sacrificando un bien cierto por una ruptura abierta con nuestro Gobierno. Retiren o no el pedido de 100 copias, espero que usted tendrá cuidado en cualquier comunicación que tenga con Lord Wellesley de transmitirle sólidas garantías de su voluntad y afán de atender a los deseos del Gobierno y de promover el principal y original objeto de sus publicaciones de usted, a saber, una unión de sentimientos y una confianza mutua entre todo lo que queda del Imperio español y Gran Bretaña” (Blanco White, 2010, p. 72).

¿Cómo se consigue tal fin manteniendo, o más bien aparentando mantener, la independencia que honra a cualquier periodista? Las recetas de Lord Holland, en carta de 26 de septiembre de 1810, son diáfanas: dilatando las discusiones y realizando las debidas elipsis para evitar el engorro de decir lo que se piensa y conseguir el favorable estatus de ser "del agrado y del gusto de los que están en el poder” (Blanco White, 2010, p. 71). No extrañará, entonces, que a niveles oficiales la libérrima línea editorial seguida por Blanco en el primer número de El Español le hubiera causado "problemas de conciencia o si se quiere prudencia" (Blanco White, 2010, p. 362) al subsecretario del Foreign Office, según le comunica a Charles Richard Vaughan, secretario de la legación británica en España, porque encuentra que algunos pasajes “demasiado ásperos” pueden indisponer "los ánimos de los amigos que creemos tener en ese país" (Blanco White, 2010, p. 362). Con el peso que da haber hecho una nutrida suscripción al periódico, William Hamilton deja temblando la libertad de opinión que aguarda a Blanco en fecha bien temprana, puesto que el despacho entre los funcionarios británicos data del 12 de mayo de 1810, al advertir que "Los siguientes números serán revisados, y por supuesto no se permitirá que quede ningún pasaje ofensivo" (Blanco White, 2010, p. 362). Se ve que las cosas no estaban para bromas en medio de la campaña contra Francia, mucho menos si lo que se disputaba era la ansiada mediación de Inglaterra en el conflicto americano que la situaría, según sus expectativas, en un lugar privilegiado en el nuevo orden trasatlántico.

Si los ingleses veían en El Español una eficaz arma de penetración e influencia en el imperio hispánico, el gobierno español no tendrá otra mira que silenciar su opinión, preferentemente en América. En medio de esa tensión opuesta estaba Blanco y la resolvió claramente a favor de Inglaterra, no sólo porque la opción de la mordaza hispánica no le podría interesar a ningún periodista sino porque estaba convencido de encontrarse "en medio de la nación más célebre en conocimientos de política; tengo la fortuna de oír 
a los hombres más sabios, y de más experiencia en esta ciencia difícil, que no se puede aprender bien sino en la práctica, y no me ocupo de otra cosa que en consultar con ellos y transmitir sus luces a mis compatriotas" ( $E l$ Español, VII, 30/X/1810: 86). Ahora bien, estas "luces", podían ser teóricamente irreprochables, pero no servían, ni a la Junta Central ni a la Regencia, como medidas políticas ecuánimes hacer, por ejemplo, pactos particulares, tal cual se recomendaba desde Inglaterra, y se hacía eco El Español, con cada uno de los gobiernos independientes que se iban declarando en América. Acuerdos que, indiscutiblemente también, se convertirían en lesivos para los territorios que mantenían la lealtad a la Corona. Lo curioso es que no solo con respecto a España la línea del periódico podía resultar inconveniente, a veces desde América también se lo advertían. Así, Juan Germán Roscio, secretario de Asuntos Exteriores de la Junta de Caracas, en carta de 28 de enero de 1811, le indicaba con amabilidad que las cosas no se veían igual desde América, es decir, desde el escenario central de los acontecimientos, que desde Europa (El Español, XVI, 30/VII/1811: 296).

En la correspondencia con sus mentores británicos, Blanco no se abandona a la queja, al contrario, se muestra pudoroso a la hora de lamentar su situación o pedir para sí mismo. Sin embargo, a Robert Southey, al que dirige cartas más personales, le confiesa en julio de 1812 las dificultades extremas a las que lo han abocado las desavenencias con su impresor francés y las gestiones que lleva a cabo el coronel Juan Murphy, andaluz de nacimiento como Blanco y su amigo y benefactor en horas bajas, "para ver si me puede conseguir un puesto en el Foreign Office" (Blanco White, 2010, p. 300). También a Andrés de la Vega le deja clara su situación:

El Gobierno español ha logrado atemorizar de manera a los que querían leerlo en América, que he recibido cartas de Jamayca (único punto adonde tenía venta) de que, habiendo puesto en un calabozo a dos personas que lo llevaban al continente, ya no hay salida para los números. Aun quando la venta de aquí y los cien ejemplares que van a Cádiz pagan los gastos, nada me queda por un trabajo ímprobo, que me impide ganarme la vida de otra manera. El único modo de que subsista este papel sería que este Gobierno tomase igual número de ejemplares que toma a Pelletier: pero esto no lo quieren hacer sin saber la opinión de Sir Henry Wellesley y Mr. Vaughan, sobre el carácter e influxo político de este periódico (Blanco White, 2010, p. 323).

Esa carta se escribía el 3 de agosto de 1812, un mes después, el 8 de septiembre, Vaughan recomendaba a Hamilton "que el Foreign Office se 
apropie de Blanco y le mantenga perpetuamente adjunto a ustedes con un buen salario"8 (Blanco White, 2010, p. 365), valorando el talento de Blanco, "escribe muy clara y convincentemente" (365); su idiosincrasia afín a Inglaterra, "él mismo y su amigo Vega son los únicos españoles que yo haya conocido que consideraban los asuntos españoles como hombres ingleses" (365); lo dispuestas que estaban las páginas de El Español para dar cauce a los intereses británicos, "el Español [...] hace un gran bien y siempre está listo para hacer incluso más" ( 365); y lo conveniente de una intervención en un panorama que se les antojaba desmadrado "por la impotencia e ineficacia de los españoles gobernando su país y dirigiendo sus recursos" (365).

Blanco había comenzado sus traducciones e informes al Foreign Office en noviembre de 1811; en marzo del siguiente año le había comunicado a Hamilton su liberación del impresor francés, lo cual lo dejaba en la conveniente situación personal de ser dueño de su propio periódico y en la inconveniente de la desprotección económica, por lo que mantenía "la más perfecta seguridad en la amabilidad que usted me ha mostrado, de que si hubiera una oportunidad de aumentar el apoyo que esa administración me ha concedido hasta ahora, usted añadirá ese favor a aquellos que ya reconozco" (Blanco White, 2010, p. 217). Efectivamente, el Foreign Office resolverá los acuciantes problemas económicos de Blanco con "una especie de colocación, que puedo calcular con una especie de pensión de 250 libras por año" (Blanco White, 2010, p. 304), según le contaba amargamente a Southey en octubre de 1812, y una humillante forma de pago:

Se me paga del dinero del servicio secreto exactamente igual que a esos que traicionan a su país, y si esto lo supieran mis enemigos, sería un punto zanjado para ellos, el que yo podría hacer lo que fuera por dinero. Preferiría una pensión de cien libras por servicios pasados a cuatro veces ese dinero de esta manera (Blanco White, 2010, p. 304).

Diferente es la memoria que guarda, o quiere transmitir, cuando escribe su autobiografía. Ahí la pensión de 250 libras, que fue "la principal ayuda recibida en medio de mis enfermedades y el medio que me ha permitido educar a mi hijo" (Blanco White, 1975: 203-204), no es algo que pueda inquietar su honor ni extender sospecha alguna sobre El Español:

\footnotetext{
${ }^{8}$ En el original puede leerse: "Indeed I strenuosly recommend it to you to lay an embargo upon Blanco for the Foreing Office" (Blanco White, 2010, p. 363). Al dar la versión española, la traductora señala que otra posible traducción sería: "requise a Blanco" (365).
} 
Para concluir todo lo que creo justo y necesario decir con respecto a mi pensión, declaro que en ninguna ocasión ninguna de las personas de las cuales ha dependido en distintos momentos la continuación de esta ayuda han intentado ejercer ninguna influencia sobre mí (...) he estado tan libre de influencias como si mi principal medio de subsistencia hubiera sido una propiedad heredada (Blanco White, 1975, p. 206).

Esas son las dos versiones que el propio autor da del panorama en el que desarrolló, hasta su agotamiento en 1814, su labor al frente de El Español. Su esfuerzo, los asuntos que trata en su periódico y en sus cartas, el punto de vista y la vehemente defensa de los derechos americanos, no desdecirá del todo que Blanco defendió asuntos en los que creía, pero parece claro, clarísimo en las cartas firmadas por los británicos, que la correlación de fuerzas europeas se jugaba en territorio americano y, tanto El Español como su editor, tenían un papel asignado en el pulso mantenido por Su Graciosa Majestad con la Francia napoleónica, no digamos en las ambiciones que el riquísimo panorama del Nuevo Mundo despertaba con el hundimiento del imperio hispánico.

En sus cartas, Blanco va dando cuenta de su afanosa recopilación de materiales, sean periódicos americanos, libros o informes, que, junto al contacto, epistolar o personal, con españoles y criollos, y los comentarios, más o menos contrastados, que dejaban caer los invitados de Holland House, van formando su cambiante impresión del curso de la insurrección americana. Siempre defendió que la extrema dureza española enconaba los ánimos americanos -"El terror puede someter las mentes por un momento; pero el odio sobrevivirá a su impresión" (Blanco White, 2010, p. 216), anotaba en el informe al Foreign Office titulado "Un bosquejo de los disturbios en el reino de México, desde julio de 1808"-, convencido estaba, y por eso intentaba convencer, de que "las impolíticas medidas del Gobierno español" (Blanco White, 2010, p. 224) eran las causantes y las avivadoras del fuego emancipador en América, necesitándose, para que las aguas volvieran a su cauce (no a un nuevo cauce), la intervención de Inglaterra -"Nada, por tanto, puede devolver la tranquilidad sino la amistosa interferencia de Gran Bretaña" (Blanco White, 2010, p. 216)-.

Sin embargo, la acción política española con respecto a América no iba a variar sustancialmente. No hay más que echarle un vistazo a la carta del duque del Infantado a Holland, fechada el 6 de abril de 1813, para hacerse una idea de los aires que corrían en las altas esferas peninsulares, dispuestas a no transigir "con nuestros insurrectos de América" (Blanco White, 2010, p. 390), con los que podía intentarse cualquier cosa menos mostrar "de- 
masiada debilidad” (Blanco White, 2010, p. 390). No creía el duque en la predicación de Blanco basada en la "suavidad" y la "persuasión" frente "a una gente que no quiere escuchar otras que la de su total emancipación" (Blanco White, 2010, p. 390). En el rechazo americano a la nueva Constitución cifraba el duque que el conflicto con los territorios ultramarinos no se explicaba desde perspectivas administrativas, ni se detenía con cambios políticos. Su conclusión era palmaria y paradójica, Blanco no tenía un buen conocimiento de los asuntos americanos, pero sí planteaba con acierto sus críticas a las Cortes de Cádiz:

Le confieso que, a pesar de toda mi inclinación a ver restablecida la buena amistad entre las provincias de América las de la Península mediante la suavidad y la persuasión, no puedo compartir la opinión del señor Blanco sobre la posibilidad de éxito, aunque por lo demás estoy muy satisfecho de su manera de ver los asuntos y los sucesos políticos de España; yo creo que si tuviera datos sobre la naturaleza, el espíritu y la dirección de la revolución americana tan exactos como parece tenerlos de la situación en España, quizá su opinión se modificara a favor del sistema adoptado por el Gobierno (Blanco White, 2010, p. 390).

Postura diferente es la de Jovellanos en carta a Holland de 17 de agosto de 1811, en los inicios de la insurrección americana. En ella se destaca la situación "crítica; los medios, pocos; las necesidades inmensas" (Jovellanos, 1970, p. 235) en la que se encuentra España, lamentando la falta de reconocimiento a los esfuerzos gubernamentales. En ese contexto incluye una referencia a Blanco, sin haber leído todavía su periódico, basándose en la opinión generalizada en los círculos en los que se mueve para los que $E l$ Español es un foco avivador del "fuego" independentista, no bastando, ya en opinión de Jovellanos, para explicar la línea seguida por el periódico la idiosincrasia de su editor, esa "cabeza llena de la manía y cavilaciones democráticas" (235) que, sobra decirlo, iba a cambiar notablemente en breve tiempo. De ahí que la carta incluya una reflexión final sobre las posturas británicas hacia el Nuevo Mundo:

Tengo por tanto gran consuelo en saber de Vm. las miras benéficas de su gobierno hacia la España; pero quisiera que los comerciantes ingleses no las frustrasen por su codicia. En este punto, como en el principal de nuestra lucha, la suerte de España está en manos de Vms. (236-237).

Las contradictorias posiciones de Blanco con respecto a América, quizá respondan a que no calibró el alcance del movimiento emancipatorio 
americano al estar las miras de El Español puestas en el ataque a la política española y en los asuntos europeos, aunque los temas de los artículos del periódico puedan despistar de su objetivo editorial. Así, en carta a Hamilton de 11 de marzo de 1812, menoscababa la entidad de los líderes de la insurgencia, no apreciaba el crecimiento de la conciencia independentista, ni la envergadura del cambio que se iba instalando en todos los puntos cardinales de la América hispánica:

La ignorancia general que prevalece entre la masa de la gente, y la falta de líderes sensatos y audaces que pudieran establecer algún sistema sólido de independencia, siempre inclinará a los americanos españoles a sus anteriores hábitos de subordinación siempre que se los libere de antiguos agravios (Blanco White, 2010, pp. 224-225).

El mismo despiste mostraba ante los códigos políticos de los americanos, por lo que, si se decretaba la independencia en Caracas, Blanco no le concedía mucho futuro al no casar, según su particular opinión, con las costumbres hispánicas:

Estoy cada día más convencido de que los locos planes de independencia absoluta están lejos de ser apreciados por la masa del pueblo; más aún, concibo que Caracas, donde un puñado de hombres los han puesto en práctica, debe de estar ya harta de republicanismo. Está en directa oposición con los hábitos e ideas generales de los españoles de toda descripción (Blanco White, 2010, p. 225).

En uno de los informes enviado a Hamilton, al hilo del comentario de las noticias dadas en la Gaceta de Buenos Aires entre el 5 de junio y el 31 de julio de 1812, destaca la atracción de los americanos por "ese tipo de mímica que prevaleció en Francia durante los primeros episodios de la revolución" (Blanco White, 2010, p. 236) e insiste en considerarla "opuesta a los hábitos, maneras y carácter de los españoles" (Blanco White, 2010: 236) aunque el coladero hacía América de ese exceso de afrancesamiento hubiera partido, según señalaba en informe anterior fechado el 11 de noviembre de 1811, de las muy liberales Cortes de Cádiz que atolondradamente se esforzaban en "divertir a los americanos con proclamaciones filosóficas", dando alas "al partido del que más tenían que temer" (Blanco White, 2010, p. 179).

Las "Conversaciones americanas sobre España y sus Indias" (El Español, XXV, 30/5/1812: 3-27), en la que Blanco traza un hipotético diálogo entre un cura criollo, su sobrino, un funcionario andaluz destinado en Indias y un cacique indígena, ilustra las ideas antiliberales que el editor había ad- 
quirido en Inglaterra. Esta pieza ha sido tomada en alguna ocasión como un documento ilustrativo del sentir americano frente a España, cuando lo que en ella puede leerse es una diatriba contra la soberanía popular, un diagnóstico sobre las funestas consecuencias de la Independencia, un ataque frontal a los planteamientos políticos liberales, una moderada postura hacia la esclavitud y una condescendiente mirada sobre la población de la América hispánica. Por tanto, no son los asuntos tratados en esta composición literaria lo fundamental de ella, sino el efecto buscado con su disposición en el periódico. El diálogo inaugura de forma amena el número XXV de El Español para, a continuación, una vez predispuestos incluso jocosamente los lectores, incluir copia de la flamante Constitución de Cádiz, la más liberal que se había hecho hasta el momento en Europa. De no bastar con esto, la "Carta de Jamaica" de Simón Bolívar serviría para indicar cuál fue el centro de los ataques de Blanco y por tanto el objetivo de su medio de expresión, porque en ella no se contempla que El Español pueda leerse como foco difusor del ideario americano sino como muestra de "la naturaleza de los gobiernos españoles, sus decretos conminatorios y hostiles, y el curso entero de su desesperada conducta" (1985, p. 64)9.

Alguna vez compartió Blanco la idea de que la senda de la civilización seguía su peregrinaje hacia occidente -"estoy cada día más convencido de que el momento ha llegado en el que las Artes, las Ciencias y la Felicidad que pronto van a desaparecer de Europa, se cobijarán en las colonias españolas de América y allí florecerán hasta el más glorioso estado de prosperidad" (Blanco White, 2010: 121)-, en su ideario, más que nada para salvarse de los filósofos que apostaban por el Contrato Social. No contó con que las elites ilustradas de América tenían sueños parecidos, forjados en ideas y lecturas compartidas. No contó tampoco con que, en España, ni liberales ni conservadores iban a contemplar impasibles el ocaso territorial, ni a tolerar con paciencia las ansias emancipadoras de los criollos y mucho menos iban a amoldarse a los intereses británicos para concederles un papel principal en el conflicto hispánico, por el que tanto había abogado El Español. Descubrió, finalmente, que no había voluntad de seguir las pautas marcadas por su periódico ni a un lado ni a otro del océano. A finales de mayo de 1814, dos meses después del regreso de Fernando VII al trono con renova-

\footnotetext{
${ }^{9}$ Sin embargo, Roberto Breña considera que "la lucidez de Blanco y la información de la que disponía hicieron de El Español un punto de referencia obligado para los patriotas americanos" (2002, p. 3). Más acertada parece la postura de Rafael Herrera Guillén al indicar, remitiendo a la "Carta de Jamaica", que "los héroes americanos lo saludaron [a Blanco] como última palabra de legitimación sobre sus deseos independentistas” (2010, párr. 22).
} 
dos bríos absolutistas, dispuesto a anular las reformas emprendidas por las Cortes de Cádiz y a desatar la represión sobre los liberales, Blanco le envía una carta personal a Hamilton considerando que su esfuerzo al frente del periódico no tenía valor alguno porque ya no conducía al logro de sus fines:

No hay partido en mi país que un escritor bien intencionado pueda apoyar con la mínima perspectiva de éxito. Hasta ahora he atacado a los jacobinos españoles, y debería estar, en este momento, obligado a hacer lo mismo con los ciegos partidarios del antiguo régimen quienes, sin duda, están apoyados por el grueso de la nación. Pero lo que pudiera ganar contra éstos, se volvería a favor del partido ahora vencido, quienes probablemente se aprovecharán de cualquier oportunidad de excitar a la sedición y promover la anarquía, sus únicos recursos en el presente estado de cosas. En cuanto a las colonias, habiéndosele restaurado la soberanía al rey, no tienen pretexto para retirar su antigua lealtad, y deben someterse o estar [en] una disyuntiva en la que no veo qué parte tomar sin chocar con mis principios de honor o de justicia (Blanco White, 2010, p. 273).

Esta decepción no era nueva. Dos años antes, en "Contestación. A la Segunda Carta de un Americano al Español en Londres”, en la que debatía el fracaso de la campaña emprendida por el periódico para que el conflicto americano se resolviera por medio de la conciliación arbitrada por Inglaterra, había declarado que ya sólo se dirigiría a los americanos, "que son los únicos que se muestran inclinados á oírme" (El Español, XXVIII, 30/ VIII/1812, p. 285), pero lo cierto es que América y sus asuntos dejarán de ocupar espacios principales en el periódico desde mediados de 1812. En abril de 1813 justificaba su silencio aludiendo al escaso seguimiento práctico de su doctrina, no a que el periódico hubiera dejado de tener lectores o escasearan las noticias:

No porque de algún tiempo a esta parte rara vez se nombra a la América española en este periódico, dejo de acordarme con frecuencia de aquellos países verdaderamente desgraciados. Pero como las cosas se han puesto en términos en que nadie puede oír razones por fuertes y poderosas que sean, y nada me es más repugnante que el escribir por sólo declamar, creo que lo más útil es interrumpir pocas veces este silencio (El Español, n. XXXVI, VI/1813: 328).

Si los límites de la libertad de expresión de José María Blanco White estuvieron, como puede apreciarse en las cartas cruzadas durante los años de 
edición de El Español, seriamente vigilados, cuando no dirigidos, los flancos de la verdad de su línea editorial se encuentran en el efecto que buscaba para la causa defendida, por lo que, al no producirse aquel, esta dejaba de tener importancia. Es Fernando Durán el que advierte que lo anotado en la Observation on heresy and orthodoxy - "libre de los compromisos literarios que me habían ocupado durante los cuatro años precedentes al servicio de Inglaterra tanto como al de mi país natal" (2005, p. 227)-, no es tanto una franqueza del autor sobre su situación en los años dedicados a El Español, como uno de los argumentos que Blanco esgrimía en 1835 para ganar "el favor del público británico" (pp. 227-228), mostrando "sus méritos patrióticos ingleses" (p. 228. Las cursivas pertenecen al texto). Quizá sólo faltaría acotar que, si fueron "servicios", estos sólo podrían haber sido del interés de las instituciones inglesas, porque desde España, en plena guerra de Independencia con los territorios americanos, no podían tomarse como una ayuda los continuos ataques de El Español a su política y, desde América, los planes autonomistas del gusto europeo no colmarían ya sus miras emancipadoras.

\section{REFERENCIAS}

Blanco White, J. Ma . (1810-1814). El Español [Hemeroteca Digital de la Biblioteca Nacional de España]. Londres: Imprenta de R. Juigné.

— . (1971). Antología. Vicente Llorens (ed.). Barcelona: Labor.

. (1975). Autobiografía de Blanco White. Antonio Garnica (ed.). Sevilla: Universidad de Sevilla.

- (1993). Conversaciones americanas y otros escritos sobre España y sus Indias. Manuel Moreno Alonso (ed.). Madrid: Ediciones de Cultura Hispánica.

. (2010). Epistolario y documentos. Textos reunidos por André Pons. Martin Murphy (intro.). Oviedo: Instituto Feijoo de Estudios del Siglo XVIII.

Bolívar, S. (1985). Doctrina del Libertador. Agustín Mijares (pról.); Manuel Pérez Vila (comp., notas y crono.). Caracas: Biblioteca Ayacucho.

Breña, R. (2002). "José María Blanco White y la Independencia de América: ¿una postura pro-americana?” [versión electrónica] Historia Constitucional (revista electrónica), 3.

Durán, F. (2005). José María Blanco White o la conciencia errante. Sevilla: Fundación José Manuel Lara.

Herrera Guillén, R. (2010). "Blanco White y América. La escisión del mundo hispánico" [versión electrónica]. Scienza \& Politica. Per una storia delle dottrine, 43(22), diciembre. 
Jovellanos, M. G. de (1970). Obras, I: Epistolario. José Caso González (ed.). Barcelona: Labor.

Menéndez Pelayo, M. (1967). Historia de los heterodoxos españoles, $2^{\text {a }}$ edic., vol. II. Madrid: Biblioteca de Autores Cristianos.

Moreno Alonso, M. (2002). Divina libertad: la aventura liberal de D. José María Blanco White, 1808-1824. Sevilla: Ediciones Alfar.

Pons, A. (2006). Blanco White y América. Oviedo: Instituto Feijoo de Estudios del Siglo XVIII. 